\title{
Genetic determinism of the cellular immune reaction in Drosophila melanogaster
}

\author{
Y. CARTON, F. FREY \& A. NAPPI* \\ Laboratoire de Biologie et Génétique Evolutives, CNRS 91198, Gif sur Yvette, France and *Department of Biology, \\ Loyola University of Chicago, 6525 North Sheridan Road, Chicago, IL 60626, U.S.A.
}

\begin{abstract}
Larvae of Drosophila melanogaster produce a haemocytic reaction against eggs of the parasitoid Leptopilina boulardi, which leads to the formation of a multicellular capsule surrounding the foreign object. Melanization resulting from the conversion of phenol to $o$-quinones frequently accompanies the cellular reaction. Although various cytological and biochemical aspects of this reaction have been investigated, very little is known about genetic determinism of the insect immune response. The heredity of the capacity to encapsulate was analysed by comparing 16 reciprocal crosses made using inbred resistant and susceptible parental strains. We conclude that differences in the encapsulation capacity of $D$. melanogaster are inherited autosomally, with the reactive phenotype showing complete dominance over the non-reactive one. There were neither sex-linked nor maternal effects. The results of all crosses suggest a single major segregating locus with two alleles and complete dominance of the resistant allele, with cytoplasmic factors and minor modifying genes acting on the major locus.
\end{abstract}

Keywords: Drosophila, encapsulation, genetic control, immunity, parasitoid.

\section{Introduction}

Against parasites and other non-self components that are too large to be phagocytosed by individual cells, insects produce a blood cell or haemocytic reaction that leads to the formation of a multicellular capsule surrounding the foreign object. Melanization resulting from the conversion of phenol to $o$-quinones frequently accompanies the cellular reaction and has long been considered an important component in the immune response of insects (Taylor, 1969). The formation of melanotic capsules is a consistent feature of the immune response of Drosophila larvae against various parasitoids (Rizki \& Rizki, 1984; Nappi \& Carton, 1986), and when attempts are made to inhibit the formation of melanin, the capacity of host larvae to form melanotic capsules is diminished (Nappi, 1973). Similar results have been documented in another parasitized insect (Brewer \& Vinson, 1971).

Because the phenol oxidase enzyme complex is involved in the initial stages of the biosynthesis of melanin, considerable interest has been focused on this enzyme system as a major component of the cellular immune responses of insects and other arthropods
(Ratcliffe, et al., 1985; Götz \& Boman, 1985). Some investigators (Söderhall, 1982; Ashida et al., 1982; Ratcliffe et al., 1984; Leonard et al., 1985) have even proposed that the phenoloxidase system may function as the non-self recognition system in anthropods.

At present, very little is known about genetic determinism of the insect immune response. The only investigations, which are incomplete, were made by Schlegel-Oprecht (1953) and Walker (1959). Cross experiments between two field populations of $D$. melanogaster with opposite defense reactions to eggs of the parasitic wasp Leptopilina heterotoma, support the hypothesis of a polygenic system with partial dominance for capsule formation. The genetics of biogenic amine metabolism, melanization and sclerotization is well documented in $D$. melanogaster (Wright, 1987). In this species, the phenol oxidase system is comprised of three pro-enzymes which interact with at least six other protein components in a cascade of reactions to produce an active enzyme (Ohnishi, 1954; Mitchell \& Weber, 1965; Seybold et al., 1975). The three proenzymes are encoded by different genes (Rizki et al., 1985).

We have previously demonstrated, using the isofemale strain method, a high genetic variability of the encapsulation ability among a wild African population 
of Drosophila against the egg of the parasitic wasp Leptopilina boulardi (Carton \& Bouletreau, 1985; Carton \& Nappi, 1991). This resulted in our obtaining two inbred lines, a non-reactive or susceptible line, and a reactive or resistant line. In this work, we used these two lines to identify the various genetic components controlling the cellular immune reaction. Our purpose was to determine the relative contributions of each component, and to ascertain what genetic determinism (simple gene model or not) is concerned. The data obtained from 16 crosses (parental, $F_{1}, F_{2}$ and backcrosses) were found to fit a single one-gene Mendelian model.

\section{Materials and methods}

\section{Origin of strains}

The isofemale line method (Hoffman \& Parsons, 1988) was used to screen and select the inbred strains of $D$. melanogaster with opposite immune capacities with respect to the parasitoid $L$. boulardi. Since 1980, 22 isofemale lines established from an African population of Drosophila melanogaster (Brazzaville, Republic of Congo) have been kept in separate laboratory cultures (Carton \& Bouletreau, 1985). This method permits us to maintain, over several years, the capacity of the $D$. melanogaster population to encapsulate. Thus, in the year 1989 , we again created a mass culture starting from five females per line (i.e. 110 females) from the set of isofemales lines established in 1980. To develop our biological model, we used this approach to select for a highly reactive strain ( $\mathrm{R}$ strain) by crossing for two successive generations individuals issued from the mass culture created during 1989, which exhibited an encapsulation that contained melanized and encapsulated parasites in their abdomen after infection (Carton et al., 1986). The non-reactive strain (S strain) was obtained from the isofemale line whose progeny showed the lowest immune capacity (Carton \& Bouletreau, 1985); after 9 years of laboratory culture the level of encapsulation in this susceptible line was only about 2 per cent.

The parasitic wasp $L$. boulardi, used in this study, was caught in the same locality as the host. To minimize the genetic variation of the parasite's ability to evade encapsulation (Carton et al., 1989), all the individuals used for this investigation were derived from a single female originating from this locality.

\section{Bioassay procedure}

Bioassays were conducted in a plexiglass box containing two batches of 20 host larvae deposited each on a small disc of artificial medium. One batch corresponded to the strain to test, the other one to the control, i.e. the reactive strain. Four females of $L$. boulardi were introduced for $8 \mathrm{~h}$ into the box and oviposited in the second instar larvae ( $24 \mathrm{~h}$ after hatching). Forty hours after the end of infection, host larvae (early third instar) were dissected and the status of the parasitoid egg determined (encapsulated or not). All experiments were conducted in a constant temperature room held at $25^{\circ} \mathrm{C}$.

The encapsulation rate (per cent) was calculated by the ratio of the encapsulated egg number to the recovered egg number. For each cross, four to 14 replicates (each with 20 larvae submitted to infection) were done.

Dissection of larvae did not permit us to differentiate the sex. However, by careful dissection and analysis of reproductive organs of very late third instar larvae of Drosophila, we were able to identify on a few animals the sex with an error of less than 5 per cent.

For the test with a single gene model, infected larvae were classified into two classes; the resistant ones (larvae which encapsulated at least one egg) and the susceptible ones (larvae which did not encapsulate).

\section{Cross procedure}

Two generations of reciprocal crosses (Table 1) between the reactive or resistant $(\mathrm{R})$ and the non-reactive or sensitive $(\mathrm{S})$ strains were performed to yield 16 lines of progeny: two parental strains, two $F_{1}$ hybrids, four separate backcrosses to both the $S$ and $R$ strains and $F_{2}$ hybrids. Each line was tested for encapsulation capacity at the larval stage as described above.

\section{Statistical analysis}

A test of normality of data values was made utilizing the Shapiro-Wilk statistics $(W)$, a univariate procedure for sample size less than 2,000 , using the SAS general linear model procedure (SAS Institute Inc., 1988): low values of $W$ lead to rejection of the null hypothesis (i.e. data values are a random sample from a normal distribution).

Analyses of variance (ANOVA) using the SAS general linear model procedure were performed to determine the mode of inheritance of the cellular immune capacity. Comparisons were made according to the methods proposed by Wahlsten (1979) and de Belle \& Sokolowski (1987) and included the following which are referenced in Table 1 (crosses contrasted are given in parentheses. Cross numbers refer to those described in Table 1):

1 S versus R parental strains (1 vs 2 ) to test the differences between the two parental lines. 
Table 1 Encapsulation rate of the third instar larvae of crosses between reactive $(\mathbf{R})$ and sensitive $(\mathbf{S})$ D. melanogaster selected strains

\begin{tabular}{|c|c|c|c|c|c|c|}
\hline $\begin{array}{l}\text { Cross } \\
\text { Number }\end{array}$ & Mother $\times$ Father & $\begin{array}{l}\text { Number of } \\
\text { replicates }\end{array}$ & $\begin{array}{l}\text { Number of larvae } \\
\text { tested }\end{array}$ & $\begin{array}{l}\text { Encapsulation rate } \\
(\text { Mean } \pm \text { S.E. })(\%)\end{array}$ & $\begin{array}{l}\text { Control } \\
(\mathbf{R} \times \mathbf{R})(\%)\end{array}$ & $W^{*}$ \\
\hline \multicolumn{7}{|c|}{ Parental strains } \\
\hline 1 & $\mathbf{S} \times \mathbf{S}$ & 14 & 139 & $2.9 \pm 1.9$ & 82.6 & 0.49 \\
\hline 2 & $\mathbf{R} \times \mathbf{R}$ & 14 & 188 & $82.6 \pm 3.8$ & - & 0.93 \\
\hline \multicolumn{7}{|c|}{ Reciprocal $F_{1}$ hybrids } \\
\hline 3 & $\mathbf{S} \times \mathbf{R}$ & 8 & 95 & $94.2 \pm 1.4$ & 87.0 & 0.91 \\
\hline 4 & $\mathrm{R} \times \mathrm{S}$ & 8 & 89 & $84.7 \pm 3.6$ & 89.5 & 0.91 \\
\hline \multicolumn{7}{|c|}{ Reciprocal backcrosses } \\
\hline 5 & $\mathbf{S} \times(\mathbf{S} \times \mathbf{R})$ & 6 & 66 & $53.3 \pm 5.7$ & 82.6 & 0.96 \\
\hline 6 & $\mathrm{~S} \times(\mathbf{R} \times \mathbf{S})$ & 5 & 49 & $54.3 \pm 8.9$ & 78.7 & 0.86 \\
\hline 7 & $\mathbf{R} \times(\mathbf{S} \times \mathbf{R})$ & 5 & 57 & $85.9 \pm 3.2$ & 89.4 & 0.91 \\
\hline 8 & $\mathbf{R} \times(\mathbf{R} \times \mathbf{S})$ & 5 & 52 & $90.0 \pm 5.1$ & 85.5 & 0.98 \\
\hline 9 & $(\mathrm{~S} \times \mathrm{R}) \times \mathrm{S}$ & 4 & 41 & $59.2 \pm 9.6$ & 79.3 & 0.75 \\
\hline 10 & $(\mathrm{R} \times \mathrm{S}) \times \mathrm{S}$ & 6 & 73 & $50.8 \pm 6.3$ & 78.1 & 0.95 \\
\hline 11 & $(\mathbf{S} \times \mathbf{R}) \times \mathbf{R}$ & 5 & 54 & $88.4 \pm 6.9$ & 88.3 & 0.82 \\
\hline 12 & $(\mathbf{R} \times \mathbf{S}) \times \mathbf{R}$ & 5 & 52 & $76.6 \pm 5.7$ & 88.0 & 0.84 \\
\hline \multicolumn{7}{|c|}{ Reciprocal $\mathrm{F}_{2}$ hybrids } \\
\hline 13 & $(\mathbf{S} \times \mathbf{R}) \times(\mathbf{S} \times \mathbf{R})$ & 6 & 65 & $72.4 \pm 5.8$ & 89.1 & 0.93 \\
\hline 14 & $(\mathbf{S} \times \mathbf{R}) \times(\mathbf{R} \times \mathbf{S})$ & 7 & 99 & $59.9 \pm 3.7$ & 78.3 & 0.93 \\
\hline 15 & $(\mathbf{R} \times \mathbf{S}) \times(\mathbf{S} \times \mathbf{R})$ & 7 & 66 & $66.0 \pm 7.6$ & 91.0 & 0.91 \\
\hline 16 & $(\mathbf{R} \times \mathbf{S}) \times(\mathbf{R} \times \mathbf{S})$ & 6 & 58 & $80.2 \pm 5.6$ & 86.9 & 0.95 \\
\hline
\end{tabular}

*Wilk-Shapiro statistic $(W)$ to test for normality of distribution (see text for more details).

$2 S+R$ versus $F_{1}$ to investigate complete genetic dominance or additive effect $(1+2$ vs. $3+4)$.

$3 F_{1}$ 's for deviation from an autosomal mode of inheritance ( 3 vs. 4 ), i.e. non-autosomal inheritance (sex chromosomes, permanent cytoplasmic factors, transient maternal factors).

$4 \quad F_{2}$ 's for significance of permanent cytoplasmic factors $(13+14$ vs. $15+16)$.

5 Backcrosses to females $(5+8$ vs. $6+7)$ to examine interactions between $\mathrm{Y}$ chromosome and/or $\mathrm{X}$ chromosome and all other factors.

6 Backcrosses to males $(9+12$ vs. $10+11)$ to examine interactions between the permanent cytoplasmic factors and all other factors.

\section{Test to evaluate one gene model versus additive effect model}

A more complete statistical investigation than comparison 2 (see above) can be performed to determine if experimental results fit better a complete autosomal dominance than a strictly additive pattern of inheritance. The following relationship would be present in the case of $R$ totally dominant on $S$ :

$\mathrm{S}<\mathrm{B}_{\mathrm{S}}<\mathrm{F}_{2}<\left(\mathrm{F}_{1}=\mathrm{B}_{\mathrm{R}}=\mathrm{R}\right)$.
With a strictly additive pattern and assuming the effects of resistant and susceptible alleles to be equal but opposite, $\mathrm{B}_{\mathrm{S}}$ should be intermediate between the $S$ parental strain and the $F_{1}$ because it comprises 50 per cent $S / S$ and 50 per cent $R / S$. The $F_{2}$ should not be significantly different from the $F_{1}$ because it comprises 25 per cent $S / S, 50$ per cent $S / R$ and 25 per cent $R / R$. $B_{R}$ should be intermediate between the $F_{1}$ and the $R / R$ parental strain because it comprises 50 per cent $R / S$ and 50 per cent $R / R$. We obtained the following relationship in the case of a polygenic character:

$\mathrm{S}<\mathrm{B}_{\mathrm{S}}<\left(\mathrm{F}_{2}=\mathrm{F}_{1}\right)<\mathrm{B}_{\mathrm{R}}<\mathrm{R}$.

\section{Test with a single gene model}

We used Mendelian analysis of reactive/susceptible larvae ratios to test a single gene model. A reactive larvae is recognized as an individual that has encapsulated at least one egg. In fact, in our laboratory experimental conditions of infestation (see above), monoparasitism is common and superparasitism (more than one egg per host larvae) is rare $(<8$ per cent). 


\section{Results}

\section{Stability of the wasp strain utilized for the tests}

A control ( $\mathbf{R}$ strain) was utilized for each replicate to explore possible variations in the wasp isofemale line. No correlations were observed between the experimental data and the control, as indicated below.

For parental strains:

$$
r=-0.02\left(r_{0.05}=0.35 \text {, d.f. }=27\right) \text {. }
$$

For reciprocal $\mathrm{F}_{1}$ hybrids:

$$
r=-0.04\left(r_{0.05}=0.46 \text {, d.f. }=15\right) \text {. }
$$

For reciprocal backcrosses:

$$
r=0.12\left(r_{0.05}=0.30 \text {, d.f. }=40\right) \text {. }
$$

For reciprocal $\mathrm{F}_{2}$ hybrids:

$$
r=-0.02\left(r_{0.05}=0.35 \text {, d.f. }=25\right) \text {. }
$$

Furthermore, an ANOVA test on control values of the encapsulation rate obtained with the $\mathrm{R}$ strain confirmed the genetic stability of the parasitoid line from one series of crosses to another series $(F=0.11$, $P>0.05)$. No correction of experimental values was necessary.

\section{Evaluation of the level of encapsulation in the various crosses}

The 16 crosses were tested: two parental strains, two $F_{1}$ hybrids, four backcrosses to sitter, four backcrosses to rover and $F_{2}$ hybrid lines. The mean encapsulation rates (per cent) \pm standard error (S.E.) are presented in Table 1 for all the 16 crosses.

Larvae of the selected resistant strain have significantly higher encapsulation capacity than larvae of the sensitive strain $(t=18.58$, d.f. $=26, P<0.001)$ as confirmed by replicate tests $(n=14)$. The mean encapsulation rate of the reactive strain is 82.6 per cent and for the sensitive one, 2.9 per cent.

We observed for each of 16 crosses (except for the parental non-reactive strain) that replicate data, despite their representation as a percentage, show a normal distribution (Table 1). As the data do not require arc sine transformation, we can perform a contrast ANOVA for all 16 crosses with experimental non-transformed data values.

\section{Contribution made by autosomes, sex chromosomes and cytoplasmic factors}

Contrast analysis of variance (Table 2 ) shows a highly significant difference between resistant and sensitive parental strains $(F=257.1, P<0.001)$. Dominance of the resistant character(s) is evident by comparison of parental strains with the $\mathrm{F}_{1}$ hybrid $(F=79.6$, $P<0.001)$. Reciprocal $F_{1}$ hybrids do not differ from each other, which indicates that non-autosomal inheritance is not involved $(F=0.2, P>0.05)$. Confirmations was obtained from analysis of encapsulation rates observed on male (76.1 per cent, $n=25$ ) and female (71 per cent, $n=58$ ) larvae. No significant difference was observed between the two sexes $\left(\chi^{2}=0.052\right.$, d.f. $=1$ ).

$\mathrm{F}_{2}$ comparisons were not significant $(F=2.1$, $P>0.05$ ), proving non-influence of permanent cytoplasmic factors (Table 2). Comparisons of interactions between $\mathrm{X}$ and/or $\mathrm{Y}$ chromosomes and all other factors were also not significant $(r=3.2, P>0.05)$. On the contrary, the test seems to indicate the influence of the interactions between cytoplasmic factors and all other factors, especially chromosomes $(F=7.9$, $P<0.01$ ).

\section{The type of inheritance}

The similarity of the encapsulation rate for the resistant parent cross, $B_{R}$ and $F_{2}$ implies a typical complete dominant effect (Table 3 ). This is comfirmed by comparison between the encapsulation rate observed in each reciprocal cross, $\mathrm{P}_{1}, \mathrm{P}_{2}, \mathrm{~F}_{1}, \mathrm{~B}_{\mathrm{S}}, \mathrm{B}_{\mathrm{R}}$ and $\mathrm{F}_{2}$ (Table 4) and suggests a genetic relationship based on a single gene model.

\section{Testing the fit of a single gene model}

The larvae in the different crosses, according to their cellular response to the parasitoid (reactive or nonreactive) were distributed in two classes, the resistant class and the sensitive class (Table 4). Chi-square analysis of resistant/sensitive ratios prove that these data fit perfectly a single gene, complete dominance model of inheritance. Observed ratios do not differ significantly from the expected Mendelian ratios in all the reciprocal crosses observed.

\section{Discussion}

Selection against the parasitoid $L$. boulardi resulted in the production of two D. melanogaster strains, a highly resistant strain and one highly susceptible to the parasite. These two strains cannot be considered as isogenic but rather highly homozygous because sister-brother crosses over several generations $(25$ generations for the resistant line, 210 generations for the susceptible line) have rendered these strains so far pure.

Crosses between the two selected strains of $D$. melanogaster give very useful information on the genetic determinism of the cellular encapsulation process. The ability to select rapidly a strain of Drosophila with a 
Table 2 Contrast ANOVA for encapsulation ability from crosses between reactive (R) and sensitive (S) strains of Drosophila melanogaster

\begin{tabular}{|c|c|c|c|c|c|}
\hline \multicolumn{2}{|c|}{ Source } & d.f. & MS & $F$ & $P$ \\
\hline \multicolumn{2}{|c|}{ Model (between crosses) } & 15 & 5311.9 & 30.8 & 0.001 \\
\hline \multicolumn{6}{|c|}{ Contrasts } \\
\hline 1 & $S$ versus $R$ parental strains & 1 & 44365.1 & 257.1 & 0.0001 \\
\hline 2 & Dominance & 1 & 13743.2 & 79.6 & 0.0001 \\
\hline 3 & $\begin{array}{l}\text { Deviation from an autosomal mode } \\
\text { of inheritance }\end{array}$ & 1 & 43.4 & 0.2 & 0.61 \\
\hline 4 & Permanent cytoplasmic factors & 1 & 366.4 & 2.1 & 0.148 \\
\hline 5 & $\begin{array}{l}\text { Interactions between } \mathrm{X} \text { or } \mathrm{Y} \\
\text { chromosomes factors and all other } \\
\text { factors }\end{array}$ & 1 & 552.4 & 3.2 & 0.077 \\
\hline 6 & $\begin{array}{l}\text { Interactions between permanent } \\
\text { cytoplamic factors and all other } \\
\text { factors }\end{array}$ & 1 & 1357.4 & 7.9 & 0.006 \\
\hline \multicolumn{2}{|c|}{ Error (within crosses) } & 95 & 263.8 & & \\
\hline
\end{tabular}

Table 3 Mean encapsulation rates for each reciprocal crosses studied and $t$-test comparison to test if they fit the relationships observed in a one-gene model with complete dominance

\begin{tabular}{|c|c|c|c|c|c|c|c|c|c|c|c|}
\hline Cross & $P_{1}$ & & $\mathrm{~B}_{\mathrm{S}}$ & & $\mathrm{F}_{2}$ & & $F_{1}$ & & $\mathrm{~B}_{\mathrm{R}}$ & & $\mathrm{P}_{2}$ \\
\hline Mean (\%) & 2.9 & & 53.9 & & 69.1 & & 89.5 & & 82.9 & & 82.6 \\
\hline $\begin{array}{l}t \text {-test comparison } \\
\text { d.f. }\end{array}$ & & $\begin{array}{l}11.9^{* *} \\
33\end{array}$ & & $\begin{array}{l}3.2^{* *} \\
45\end{array}$ & & $\begin{array}{l}4.6^{* *} \\
40\end{array}$ & & $\begin{array}{l}1.8^{\mathrm{NS}} \\
34\end{array}$ & & $\begin{array}{l}1.4^{\mathrm{NS}} \\
32\end{array}$ & \\
\hline Cross hierarchy & $P_{1}$ & $<$ & $\mathrm{B}_{\mathrm{S}}$ & $<$ & $F_{2}$ & $<$ & $\left(F_{1}\right.$ & $=$ & $\mathrm{B}_{\mathrm{R}}$ & $=$ & $\left.\mathbf{P}_{2}\right)$ \\
\hline
\end{tabular}

**Highly significant $(P<0.01) ; \mathrm{NS}=$ not significant.

Table 4 Chi-square analysis of reactive $(R)$ and sensitive $(S)$ larval individual ratios of D. melanogaster submitted to infection. Expected ratios are derived by assuming a 6.4 per cent probability of misclassification (obtained from observed ratios in parental $P_{1}$ and $P_{2}$ crosses)

\begin{tabular}{|c|c|c|c|c|c|c|}
\hline Crosses & $n$ & $\mathrm{R}: \mathrm{S}$ & Expected & Observed & $\chi^{2}$ & $P$ \\
\hline \multicolumn{7}{|c|}{ Parental crosses } \\
\hline$P_{1}{ }_{S \times S}$ & 139 & $0: 1$ & $0: 139$ & $9: 130$ & & \\
\hline${ }^{P_{2}} \mathrm{R} \times \mathrm{R}$ & $1134\left(^{*}\right)$ & $1: 0$ & $1134: 0$ & $989: 145$ & & \\
\hline \multicolumn{7}{|c|}{ Recriprocal crosses } \\
\hline $\mathrm{F}_{\mathrm{S} \times \mathrm{R}}$ & 184 & $1: 0$ & $166: 18$ & $163: 21$ & 0.25 & NS \\
\hline $\mathrm{B}_{\mathrm{S}} \mathrm{F}_{1} \times \mathrm{S}$ & 229 & $1: 1$ & $114.5: 114.5$ & $115: 114$ & 0.002 & NS \\
\hline $\begin{array}{l}\mathrm{B}_{\mathrm{R}} \\
\mathrm{F}_{1} \times \mathrm{R}\end{array}$ & 215 & $1: 0$ & $194: 21$ & $176: 39$ & 6.27 & NS \\
\hline$F_{1} \times F_{1}$ & 228 & $3: 1$ & $216: 72$ & $190: 98$ & 5.6 & NS \\
\hline
\end{tabular}

${ }^{*}$ Data for the $\mathrm{R} \times \mathrm{R}$ cross were obtained from all the $\mathrm{R} \times \mathrm{R}$ controls. $\left(\chi^{2}=6.63\right.$, d.f. $=1)$. NS $=$ not significant at $P=0.01$. 
high immune capacity suggests a partial genetic inheritance of this trait with a low number of genes. Based on the results obtained by the reciprocal crosses, we conclude that differences in encapsulation capacity of $D$. melanogaster are inherited autosomally, with the reactive phenotype showing complete dominance over the non-reactive one. There were neither sex linkage nor maternal effects. However, we observed that resistance in the $F_{1}$ hybrids is higher than the two parental strains. This phenomenon, which also has been observed by other investigators (Bauer \& Sokolowski, 1985) for a behavioural larval trait, may be explained by a classical heterosis effect. Contrast ANOvA comparisons also reveal the influence of interactions between permanent cytoplasmic factors and all other factors (i.e. the chromosomal components). The results of all the crosses suggest a single major segregating locus with two alleles and complete dominance of the resistant allele, with cytoplasmic factors and minor modifying genes acting on the major locus. The problem is now to discover what this major gene codes for? Such a single gene control was observed in mosquitoes selected for their refractoriness to malaria (Collins et al., 1986) or to blue tongue virus (Tabachnick, 1991).

Our present knowledge of the mechanisms regulating the cellular and biochemical changes associated with insect immunity is less than adequate to allow us to do more than speculate on the nature of the genetic control of this process. Most authors recognize the role played by certain biogenic amines and their derivates in the formation of melanotic capsules around parasites (see Gotz \& Boman, 1985) but little is understood about how the genetically encoded enzymes involved in catecholamine metabolism are activated in response to parasite infection. Phenol oxidases have long been considered to play a key role in the effector response of immune activated haemocytes against nonself (Christensen \& Tracy, 1989; Söderhall et al., 1990; Ashida, 1990), particularly in Drosophila (Nappi et al., 1991). These observations have led some investigators to link opsonic properties of the proenzyme-activating cascade with an immune recognition function (Söderhall, 1982; Ratcliffe et al., 1984; Leonard et al., 1985; Ashida \& Yoshida, 1988). It remains to be ascertained that activation of the phenol oxidase system is a result of a recognition response rather than its cause. Genetically selected strains, such as these studied here, could certainly help us to investigate this crucial step in invertebrate immunology.

In addition, haemolymph components other than catechols may also be involved in the immune response of Drosophila. Recognition-specific proteins have been found in some other insects (Söderhall et al., 1988; Ochiai \& Ashida, 1988; Richards et al., 1989; Jomori et al., 1990) and one species of crayfish (Duvic \& Söderhall, 1990).

One of our immediate concerns is to determine if our selection was specific for the parasitoid species $L$. boulardi and to ascertain if the selection process operates at the initial events of immune recognition of non-self, or at subsequent stages involving effector mechanisms (i.e. those associated with the cellular and biochemical killing responses) potentiated by the recognition process. In the work citied above (Collins et al., 1989) an interesting result was that the selected refractory line of Anopheles with Plasmodium cynomolgi was ineffective with some strains of $P$. malariae. The physiological process, totally unknown, coded by the refractory gene, appears to be specific. Working with Drosophila, it is possible that we could locate the resistant gene with known genetic markers, and perhaps later dissect its structure and function more precisely.

\section{Acknowledgements}

This research was supported by grants from NSF and CNRS under the US-France collaborative Science programme.

\section{References}

AsHiDA, M. 1990. The prophenoloxidase cascade in insect immunity. Res. Immunol., 141, 908-910.

ASHIDA, M., IWAMA, R., IWAHANA, H. AND YoShIDA, H. 1982. Control and function of the prophenoloxidase activating system, In: Payne, C. C. and Burges, H. D. (eds) Proceedings of the Third International Colloqium on Invertebrate Pathology, University of Sussex, Brighton, pp. 81-86.

ASHIDA, M. AND YoshIDA, H. 1988. Limited proteolysis of prophenoloxidase during activating by microbial products in insect plasma and effect of phenoloxidase on electrophoretic mobilities of plasma proteins. Insect Biochem., 18, 11-19.

BAUER, J. AND SOKOLOWSKI, M. B. 1985. A genetic analysis of path length and pupation height in a natural population of Drosophila melanogaster. Can. J. Genet. Cytol., 27, 334-340.

BELLE, S. DE AND SOKOLOWSKI, M. B. 1987. Heredity of rover/ sitter: alternative foraging strategies of Drosophila melanogaster larvae. Heredity, 59, 73-83.

BREWER, F. D. AND VINSON, S. B. 1971. Chemicals affecting the encapsulation of foreign material in an insect. J. Invert. Pathol., 18, 287-289.

CARTON, Y. AND BOULETREAU, M. 1985. Encapsulation ability of Drosophila melanogaster a genetic analysis. Dev. Comp. Immunol., 9, 21-219.

CARTON, Y, BOULETREAU, M., ALPHEN, J. VAN AND LENTEREN, J. VAN. 1986. The Drosophila parasitic wasps. In: Ashburner, M., Carson, L. and Thompson, J. N. (eds) The Genetics and 
Biology of Drosophila. vol. 3e, Academic Press, New York, pp. 347-394.

CARTON, Y., CAPY., P. AND NAPPI, A. J. 1989. Genetic variability of host parasite relationship traits: utilization of isofemale lines in a Drosophila parasitic wasp. Genet. Sel. Evol., 21, 437-447.

CARTON, Y. AND NAPPI, A. J. 1991. The Drosophila immune reaction and the parasitoid capacity to evade it: genetic and coevolutionary aspects. Acta Oecol., 12, 89-104.

CHRISTENSEN, B. M. AND TRACY, J. w. 1989. Arthropod-transmitted parasites: mechanisms of immune reaction. $A m$. Zool., 29, 387-398.

COLLINS, F. H., SAKAI, R. K., VERNICK, K. D., PASKEWITCH, S., SEELEY, D. C., MILlER, L. H., COLLINS, W. E., CAMPBELL, C. C. AND GWADZ, R.w. 1986. Genetic selection of a plasmodium-refractory strain of the malaria vector Anopheles gambiae. Science, 234, 607-610.

DUVIC, B. AND SÖDERHAll, K. 1990. Purification and characterization of a $\beta$ 1,3-glucan binding protein from plasma of the crayfish Pascifastacus leniusculus. J. Biol. Chem., 265, 9327-9332.

GOTZ, P. AND BOMAN, H. G. 1985. Insect immunity. In: Kerkut, G. A. and Gilbert L. I. (eds), Comprehensive Insect Physiology, Biochemistry and Pharmacology, vol. 3, Pergamon Press, Oxford. pp. 453-485.

HOFFMANN, A. A. AND PARSONS, P. A. 1988. The analysis of quantitative variation in natural populations with isofemale strains. Genet. Sel. Evol, 20,87-98.

JOMORI, T., KUBO, T. AND NATORI, s. 1990. Purifications and characterization of lipopolysaccharide-binding protein from hemolymph of American cockroach Periplaneta americana. Eur. J. Biochem., 190, 201-206.

LEONARD, C., RATCLIFFE, N. A. AND ROWLEY, A. F. 1985. The role of prophenoloxidase activation in non-self recognition and phagocytosis by insect blood cells. J. Insect Physiol., 31, 789-799.

Mitchell, H. L. AND WEBER, U. M. 1965. Drosophila phenol oxidases. Science, 148, 964-965.

NAPPI, A. J. 1973. The role of melanization in the immune reaction of larvae of Drosophila algonquin against Pseudeucoila bochei. Parasitology, 66, 23-32.

NAPPI, A. J. AND CARTON, Y. 1986. Cellular immune responses of Drosophila. In: Bréhelin, M. (ed.) Immunity in Invertebrates, Spinger-Verlag, Berlin. 13, pp. 171-187.

NAPPI, A. J., CARTON, Y. AND FREY, F. 1991. Parasite-induced enhancement of hemolymph tyrosinase activity in a selected immune reactive strain of Drosophila melanogaster. Arch. Ins. Biochem. Physiol., 18, 159-168.

OCHIAI. M. AND ASHIDA, M. 1988. Purification of a $\beta 1$,3-glucan recognition protein in the prophenoloxidase activating system from hemolymph of the silkworm, Bombyx mori.J. Biol. Chem., 263, 12056-12062.

oHNISHI, E. 1954. Activation of tyrosinase in Drosophila virilis. Annot. Zool. Jpn., 27, 188-193.

RATCLIFFe, N. A., LEONARD, C. AND ROWLEY, A. F. 1984. Prophenol- oxidase activating, non-self recognition and cell co-operation in insect immunity. Science, 226, 557-559.

RATCLIFFE, N. A., ROWLEY, A. F., FITZGERALD, S. W. AND RHODES, C. P. 1985. Invertebrate immunity: basic concepts and recent advances. Invert. Rev. Cytol., 97, 183-485.

RICHARDS, E. H., RATCLIFFE, N. A. AND RENWRANTZ, L. 1989. The binding of lectins to carbohydrate moieties on hemocytes of insects, Blaberus craniifer (Dictyoptera) and Extatosoma tiaratum (Phasmida). Cell. Tiss. Res., 275, 445-454.

RIZKI, T. M. AND RIZKI, R. M. 1984. The cellular defense system of Drosophila melanogaster. In: King, R. C. and Akai, H. (eds), Insect Ultrastructure. vol. 2, Plenum Press, New York, pp. 579-604.

RIZKI, T. M., RIZKI, R. M. AND BELlOTI, R. A. 1985. Genetics of a Drosophila phenoloxidase. Mol. Gen. Genet, 201, 7-13.

SAS INSTITUTE. 1985. SAS User's Guide: Statistics, version 5 edn, SAS Institute, Cary, NC.

SCHLEGEL-OPRECHT, E. 1953. Versuche zur Auflösung von Mutationen bei der Zoophagen Cynipidae Pseudocolia bochei Weld und Befunde über die stammspezifische Abwehrreaktion des wirtes Drosophila melanogaster Zeit. Ind. Abst. Verebungslehere, 85, 245-281.

SEYBold, W. D., MELTZER, P. S. AND MITCHELL, H. K. 1975. Phenol oxidase activation in Drosophila: a cascade of reactions. Biochem. Genet., 13, 85-108.

SODERHALL, K. 1982. Prophenoloxidase activating system and melanization - a recognition mechanism of arthropods? A review. Dev. Comp. Immun., 6, 601-611.

SODERHALl, K., ASPAN, A. AND DUVIC, B. 1990. The proPOsystem and associated proteins: the role in cellular communication in arthropods. Res. Immunol., 141, 896-907.

SODERHALL, K., ROGENER, W., SOODERHALL, I., NEWTON, R. P. AND RATCLIFFE, N. A. 1988. The properties and purification of a Blaberus craniifer plasma protein which enhances the activation of haemocyte prophenoloxidase by a $\beta 1,3$-glycan. Insect Biochem., 18, 323-330.

TABACHNICK, w. J. 1991. Genetic control of oral susceptibility to infection of Culicoides variipennis with bluetongue virus. Am. J. Trop. Med. Hyg., 45, 666-671.

TAYLOR, R. L. 1969. A suggested role for the polyphenol phenoloxidase system in invertebrate immunity. J. Invert. Pathol., 14, 427-428.

WALKer, I. 1959. Die Abwehrreaktion des wirtes Drosophila melanogaster gegen die zoophage Cynipidae Pseudeucoila bochei Weld. Rev. Suisse Zool., 66, 569-632.

WRIGHT, T. R. F. 1987. The genetic of biogenic amine metabolism, sclerotization, and melanization in Drosophila melanogaster, Adv. Genet., 24, 127-222.

WAHLSTEN, D. 1979. A critique of the concepts of heritability and heredity in behavioral genetics. In: Royce, J. R. and Mos, L. (eds) Theoretical Advances in Behavioural Genetics. Sithoff and Nordhoff, Germantown, MD, pp. 426-481. 